\title{
Criterios clínicos prácticos sobre la asignación del sexo
}

\author{
Doctor Fernando Del Corral, M. D. (*) \\ Duke University Medical Center, Durham, N. C., U. S. A. \\ Doctor E. C. Hamblen, M. D. (*) \\ Duke University Medical Center, Durham, N. C., U. S. A.
}

La asignación del sexo a un individuo, ha sido siempre un procedimiento automático y rutinario, basado exclusivamente en la apariencia morfológica de los genitales externos. En general, el aspecto morfológico coincide casi siempre con la presencia de gonadas características para cada uno de los sexos.

Existen, por otra parte, individuos que conocemos con el nom. bre de hermafroditas, en los cuales hay una discrepancia entre sus gonadas y la diferenciación sexual de los genitales externos.

Si aplicamos a toda persona la regla usual de asignación del sexo que se otorga al recién nacido, o sea aquélla basada en su apariencia genital, nos vemos en el peligro de incluir a quienes por presentar un sexo ambiguo, hacen difícil la asignación del sexo, o que adjudicado éste sin mayor duda, sus genitales no están de acuerdo con las gonadas de las cuales son portadores.

Principalmente sobre este último grupo queremos hacer especial énfasis en este escrito, ya que a pesar de ser un grupo numéricamente pequeño (1 niño entre 1.000 nacidos), no deja de ser de capital importancia.

Si a una persona con genitales externos ambiguos, por error o negligencia se le asigna un sexo, el cual por su estructura somá-

(*) "Kellogg Fellow" en Endocrinología. Centro Médico. Universidad de Duke 1958-1959. Auxiliar de Cátedra Departamento de Obstetricia, Universidad del Valle, Cali, Colombia.

(**) Profesor de Endocrinología y Profesor Asociado de Obstetricia y Ginecología. Centro Médico. Universidad de Duke. Departamento de Obstetricia y Ginecología. 
tica, parezca racional, nos vemos en el serio problema de tener que afrontar más tarde a un individuo, niño o adolescente, con genitales morfológica y funcionalmente anormales.

Equívocos en la asignación del sexo, traen consigo graves y lógicas repercusiones, tanto síquicas como morales, para el individuo mismo, así como también para las personas que lo rodean.

Estos hombres y mujeres con un sexo equivocadamente asignaà, pueden no tener gonadas que sean compatibles con su sexo, ya sea porque los ovarios y testículos coexistan en la misma persona (hermafroditismo verdadero), o que por fallas embriológicas intrínsecas presentan genitales externos mixtos o indiferenciados, como es el caso de la intersexualidad exierna.

Existen, además, casos en los cuales la morfología genital se ha alterado, en virtud de ciertas acciones endocrinas, como sucede en individuos con criptorquidismo (pseudohermafroditismo masculino). Podemos encontrar también sujetos con ovarios e hiperplasia suprarrenal congénita (pseudohermafroditismo femenino).

Normalmente, las diversas fases de diferenciación sexual están de acuerdo con el tipo de genes sexuales determinantes, formados desde la fertilización del huevo. Esto comprendie no solamente asociaciones de cromosomas tales como X X en la mujer, o X Y en el hombre, sino también la preponderáncia de genes masculinos o femeninos asociados con autosomas.

Aplicando los resultados obtenidos de los trabajos de Barr y Bertram (1) sobre cromatina sexual (agrupaciones de cromosomas o cromocentros en la periférica del núcleo), se ha hecho evidente que los cromosomas sexuales no están siempre de acuerdo con la aparente masculinidad somática, en individuos que presentan testículos escrotales y degeneración congénita de los túbulos seminíferos (2_3), u otros individuos con criptorquidismo (4-5-6). Por otra parte, los cromosomas sexuales tampoco coinciden con la feminidad somática en individuos con sindrome de Turner, o sus variantes $(7-8)$.

\section{El sexo y sus variantes}

De acuerdo con Hampson y asociados (9), deben considerars:? siete aspectos diferentes en cada individuo, para darnos una ir. the lo que en realidad el sexo representa:

1. Sexo cromosomático.

2. Sexo gonadal.

3. Sexo hormonal. 
4. Morfología de los genitales internos accesorios.

5. Morfología de los genitales externos.

6. Sexo de asignación y crianza.

7. Orientación y género (aspectos sicosexuales).

Lus primeros cinco factores enumerados permiten determinar sin duda alguna, el sexo de asignación y crianza; pero ninguno de éstos, considerados aisladamente, bastan para asignarlo debidamente.

El desarrollo del género y orientación de un individuo, se basa "en el sexo que le ha sido asignado" y en su consecuente edu. cación y crianza.

De acuerdo con Barr (10), los exámenes citológicos para la determinación del sexo son de gran utilidad para el diagnóstico diferencial, así como para la reconsideración de la embriogénesis en ciertos errores congénitos del desarrollo sexual. Este procedimiento se basa en el reconocimiento de ciertas estructuras (cariosomas), identificadas alrededor del núcleo en las células somáticas. La asociación de cromosomas sexuales $\mathrm{X} X$ en la mujer, forma un cariosoma que por su tamaño se hace visible en la periferia del núcleo. Dicha mancha se conoce con el nombre de croma. tina sexual, e individuos que presenten esta característica, en más diel $40 \%$ de sus núcleos, se identifican como portadores de cromalina positiva.

La combinación de X Y, tipo masculino, está considerada coino muy pequeña para determinar la presencia de cromatina sexual, por lo tanto ésta no se hace visible al simple examen microscópico. Los individuos que carecen de este satélite nuclear se conocen con el nombre de cromatina negativos, siendo ésta una carac. teristica peculiar al sexo masculino.

I,as i,écnicas empleadas para la determinación de estos grupos cromatinicos se hacen sobre las células provenientes de la mucosa bucal obtenidas por frotis, observaciones sobre los neutrófilos en extendidos de sangre, o también en células provenientes de otros tejidos, como la piel.

El sexo gonadal obviamente depende de la presencia de ovarios o testículos. Cuando ambas gonadas están presentes en el mis. mo individuo, se habla de bisexualidad gonadal, o sea del verdacero hermafroditismo. Sabemos que la exploración quirúrgica y el estudio microscópico de la gonada determinan el verdadero sexo en aquellos individuos que presentan genitales externos ambiguos. No obstante, la apariencia y constitución histológica de la gonada. 
no implican que ésta sea productora de las hormonas que por su morfología le son propias. Basándonos en estas observaciones podemos anotar que un testículo con células de Leydig, aparentemente normales, puede no ser productor de hormonas masculinas y, por el contrario, puede ser el responsable de la estrogenización de un individuo.

La orientación y "género" de un individuo, comprenden todas aquellas cosas y hechos que una persona hace y dice, para identificarse, asumiendo así el comportamiento de un niño u hombre o de una niña o mujer, respectivamente. El papel o "género" de una persona no se establece automáticamente al nacimiento de una forma instintiva; es el proceso acumulativo formado a raíz de las experiencias de la vida, encontradas al través de su desarro110 y aprendidas mediante la inculcación e instrucción explícita.

Para Money (11), los genitales externos representan un sello que garantiza el desarrollo del "género" en un individuo en vía de crecimiento.

Queremos contemplar, además, en este escrito lo referente al sexo legal de un individuo. Por éste se entiende el sexo bien o mal adjudicado a un recién nacido, por medio del certificado de naci. miento. Generalmente éste determina el sexo de orientación y crianza del mismo.

Según uno de nosotros (E. C. H. 32), los enigmas del sexo pueden ser dasificados en ocho diferentes tipos:

Tipo 1. Pseudohermafroditismo femenino, debido a hiperplasia congenital de las stiprarrenaĩes (Cromatina positiva). Ovarios presentes; clitoris aumentado de tamaño, pudiendo simular un pene con hipospadias; los labios pueden o no estar fusionados o aglutinados; genitales internos ginecoides; pubertad precoz androide.

Tipo 2. Pseudohermafroditismo femenino, no debido a hiperplasia suprarrenal congénita. Debido a fallas embriológicas intrínsecas o debido a virilización materna durante la gestación, por tumores (arrenoblastomas) terapia androgénica o debido al uso de los nuevos progestógenos (derivados de la Nor-testosterona). Cromatina positivos; ovarios presentes; el clítoris puede ser del tamaño de un pene y tener uretra peneal; fusión de los labios presen. te; genitales internos ginecoides; pubertad ginecoide. Sobra decir que este tipo es muy infrecuente. 
Tipo 3. Pseudohermafroditismo masculino, con genitales externos androides o ambiguos y con genitales internos predominantemente ginecoides, pero en los cuales hay ciertos vestigios androi_ des. Cromatina negativa. Testículos abdominales o inguinales; pene mediano o largo, frecuentemente con hispospadias y ocasionalmente con uretra peneal. Labios fusionados o aglutinados; infrecuentemente pueden tener el orificio vaginal separado, o seno urogenital; pubertad frecuentemente androide.

Tipo 4. Pseudohermafroditismo masculino, con genitales externos androides o ambiguos y con genitales internos predominan_ iemente androides; pero en los cuales hay ciertos vestigios ginecoides. Cromatina negativa. La pubertad puede ser androide o girecoide. Las características de estos individuos son similares a las del tipo 3.

Tipo 5. Pseudohermafroditismo mascuino, con genitales externos esencialmente ginecoides. Cromatina negativa. Testículos abdominales o inguinales; pene pequeño, labios no fusionados; vulva bien formada; vagina frecuentemente separada y ciega; geni. tales internos predominantemente ginecoides; útero generalmente ausente o pobremente desarrollado. Pubertad generalmente ginecoide.

Tipo 6. Hermafroditismo verdadero, aproximadamente el $\% 5 \%$ presentan eromatina positiva. Las gonadas pueden ser: un ovario y un testículo, o pueden ambos estar contenidos en la misma gonada abdominal (unilateral o bilateralmente). Su localización puede ser también inguinal o labio escrotal; pene de desarrollo variable; fusión de los labios variable genitales internos ginecoides y androides. La pubertad puede ser androide o ginecoide.

Tipo 7. Individuos con genitales externos e internos morfologicamente ginecoides, con cromatina negativa. Este grupo incluye a individuos con el Síndrome de Turner o síndrome de gonadas ausentes o rudimentarias. Genitales externos e internos ginecoides. No hay pubortad.

Tipo 8. Individuos con genitales externos e internos androi_ des, salvo por la ginecomastia que presentan durante la pubertad. Cromatina positiva. Este grupo incluye a pacientes con el Sindrobe de Klinefelter, que desarrollan ginecomastia durante la pubertad. Los testículos son pequeños y duros y están caracterizados por degeneración dei epitelio de los túbulos seminíferos y la presencia de células de Leydig aparentemente normales. 


\section{Desarrollo de las gonadas}

De acuerdo con Spemann (13), un tejido en estado de desarro110 avanzado, destinado a ser una estructura especial, puede ser inducido convirtiéndose en una estructura diferente, siempre y cuando sea transplantado a otra región del embrión.

Para que las gonadas adquieran un desarrollo, se requiere la presencia de inductores u organizadores, cuya naturaleza nos es aún desconocida. Las fallas en estos organizadores se traducen en ciesarrollo de una gonada fetal patológica.

Los diferentes grados o estados de desarrollo de las estructu. ras genitales premonitoras (canales de Müller o de Wolff), dependen de la presencia o ausencia de testículos fetales funcionantes durante las primeras etapas del desarrollo fetal. El funcionamiento temprano de los testículos fetales puede ser también alterado por una acción hormonal producida como consecuencia de una hiperplasia suprarrenal congénita, causando trastornos en la diferenciación de los genitales externos (persistencia del seno urogenital, etc.).

Para Grumbach y asociados (14), 'a diferenciación de la gonada primordial en testículos u ovarios, depende de un balance determinado por un número de fuerzas genéticas y antagonistas, que le son características a cada uno de los cromosomas y autosomas sexuales. Las fallas en la diferenciación de la gonada, pueden ser causadas por enfermedades maternas o fetales.

De acuerdo con la teoría monohormónica de Wiesner (15), la presencia o ausencia de testículos fetales es el factor responsable, que cuenta en la diferenciación sexual. Cuando los testículos están ausentes, o no son funcionantes, durante las primeras etapas de la vida fetal, los canales de Müller se desarrollan mientras que ios canales de Wolff permanecen detenidos en su desarrollo.

Jost (16-17), corroborando esta teoría, demostró que la castración unilateral de conejos machos, durante su estado fetal, se traduce en el desarrollo de los canales de Müller, en el lado castrado; y desarrollo de los canales de Wolff, en el lado en que el testículo fue conservado. Jost observó asimismo que la castración intrauterina de conejas en su estado fetal, no tiene repercusiones significativas sobre el grado de diferenciación sexual. Pero en cambio, cuando la castración se hace en los conejos (machos), en el mismo estado fetal, se produce el desarrollo de los canales y genitales externos típicos de la hembra, y al mismo tiempo se 
aprecia el seno urogenital. Cuando esta castración se hace tardía. mente durante la vida fetal, no es posible revitar que la diferenclación genital se haga en sentido masculino.

Gillman (18), mediante sus estudion, cemostró que los testícuios fietales se diferencian más temprano que los ovarios, durante la vida embrionaria, y anota que la subsiguiente hiperplasia que ocurre en las células intersticiales de la gonada muy posiblemente indica una actividad endocrina precoz. En los casos de mujeres simuladas, o sean aquellas que presentan cromatina negativa junto con aplasia o hipoplasia gonadal, se cree que los testículos fallaron en su diferenciación, dando campo así , a que esos individuos presenten un desarrollo genital de tipo ginecoide.

En los casos de hermafroditismo verdadero, cuando un ovario se encuentra de un lado y un testículo en el lado opuesto, en el lado del ovario, se desarrollan los canales de Müller y del lado opuesto se desarrollan los canales de Wolff, en conformidad con la teoría de Wiesner.

En los casos de pseudohermafroditismo masculino, es posible, no obstante encontrar remanentes de los cuerpos de Müller. Los testículos de estos individuos, por el hecho de que presentan abundantes células de Leydig, suponen que estas gonadas han debido tener el poder de diferenciación sexual suficiente para prevenir la formación de los canales femeninos. Esto ocurrió en tres de los once casos reportados por Hamblen y asociados (19) en 1951: en el grupo de pseudohermafroditas con cromatina negativa.

La explicació de este extraño hallazgo se ha atribuído al hecho de que los testículos fueron inhibidos en su función de diferenciación sexual, en el periodo crítico de la vida fetal.

Es evidente que estos testículos no desarrollan gametos nor. males y además es sabido que su función excretora se hace en forma aberrante, o sea estrogenizando a un individuo.

En el Síndrome de Klinefelter se cree que haya habido un ciefecto, o mejor dicho, una detención en el desarrollo de la gonada. Los hallazgos de cromatina positiva (femenina) en personas cuyas gonadas se han desarrollado principalmente en sentido masculino, sugieren la posibilidad de que ha podido haber una aberración genética, con la probable asociación de cromosoma $\mathrm{X} \mathrm{X} \mathrm{Y}$, o X Y Y. La ocurrencia familiar de este desorden están en favor en la posibilidad de que esta entidad pueda ser debida a un defecto genético. Los individuos con este síndrome son obviamente masculinos, a pesar de la ginecomastia que presentan. 
Los genitales externos ie encuentran bien desarrollados pre. sentando, además, testículos escrotales. La biopsia del testículo revela la presencia de células de Leydig, así como la degeneración del epitelio de los túbulos seminíferos. Se observa además una marcada hipergonadotropuria (elevación en la excreción de gonadotropinas urinarias).

El Síndrome de Nelson debe aplicarse a este mismo grupo de individuos, los cuales, a diferencia de los anteriores, presentan cromatina negativa y no tienen ginecomastia.

En el pseudohermafroditismo femenino, parece que la acción de los testículos, en la diferenciación sexual, se hace en virtud de una acción local, la cual se ejerce mediante inductores u orga. nizadores locales; esta acción de difierenciación no depenđa de su función hormonal, o al menos no simula la acción clínica producida por los andrógenos. Un ejemplo de este tipo se presenta en el pseudohermafroditismo femenino, debido a hiperplasia suprarrenal congénita. El efecto androgénico compromete esencialmente al seno urogenital y a los genitales externos, mientras que el des. arrollo de los canales de Müller se hace en una forma normal. Este hecho ha sido reportado por Brentnall y Javert (21-22), quienes presentan dos pseudohermafroditas femeninos, nacidos con seno urogenital y genitales externos androgenizados; las madres de estos infantes presentaban en ambos casos arrenoblastomas.

Se han presentado cambios androgénicos de los genitales externos en niñas recién nacidas, cuyas madres fueron tratadas durante el embarazo, con dosis altas y contínuas de progesterona, o sus derivados sinéticos, con el objeto de prevenir el aborto. Igual. mente se cita el caso de una niña, nacida con hipertrofia del clítoris y labios mayores simulando escrotos, hija de una madre que había venido siendo tratada con andrógenos, durante su cuarto mes de embarazo (23).

Para concluir lo relacionado con el efecto de los testículos fetales y su papel en la diferenciación sexual, debemos anotar que esta acción se hace en virtud de mediadores locales llamados organizadores o inductores.

De acuerdo con la teoría de Overzier (24), el primer desarrolio de la gonada, estimula la formación de los canales de Müller y de Wolff, antes de que la estructura anatómica de la gonada pueda ser reconocida. A este mecanismi se le llama inducción inicial. 
La construcción y desarrollo de los canales masculinos o femeninos, depende de la inducción permanente, producida como resultado del desarrollo posterior de la gonada en sentido masculi. no o femenino, o sea del estímulo constante producido por el testículo o un ovario.

Si la inducción permanente falla, como ocurre en la agenesia gonadal o durante la castración en la vida fetal temprana, cualquiera que sea el sexo genético del individuo (cromatina positiva o negativa), los canales se desarrollarán en dirección femenina, debido al estímulo de la inducción inicial.

$\mathrm{Si}$, por el contrario, la inducción inicial falla, como sucede en el verdadero agonadismo, los canales de Müller y de Wolff coexisten en la misma persona como estructuras no desarrolladas.

Varios casos de individuos genéticamente masculinos y con verdadero agonadismo, han sido descritos por uno de nosotros (E. C. H. 12).

Cómo se asigna el sexo, cuando al nacimiento los genitales externos no lo permiten

Determinación del sexo en los abortos.

Generalmente en los abortos ocurridos antes del tercer mes, se hace imposible determinar el sexo, ya sea por la falta de diferenciación de los genitales externos, como por la carencia de los productos del aborto, para su reconocimiento visual.

Bohle y Hienz (25), han sugerido que la cromatina sexual puede ser investigada en la placenta 0 en los tejidos embrionarios que usualmente se encuentran acompañando el aborto.

Es de interés, más académico que práctico, anotar que median. te estos estudios se ha logrado conocer que la incidencia de abortos del sexo masculino es mayor que la de abortos con sexo femenino.

\section{Determinación del sexo antes del nacimiento}

El sexo cromosomático de un feto in útero, se ha determinado por el estudio de la cromatina en las células obtenidas a través de la aspiración de líquido amniótico. No creemos necesario referirnos a los sistemas empleados para tal motivo, por ser estos estudios esencialmente' académicos. 


\section{Determinación del sexo durante el periodo neo-natal, o al nacimiento}

Muchas veces la ambigüedad de los genitales externos no permite adjudicar inequívocamente el sexo.

Con el objeto de evitarles a los padres un impacto sicológico, anunciándoles que el hijo que les acaba de nacer es un "hermafrodita", debemos tratar de explicar racionalmente el problema, manifestándoles que el infante no tiene aún sus genitales bien desarrollados. Debe añadirse, además, que para completar su desarrollo genital, se harán necesarios tratamientos hormonales o quirúrgicos.

Bohle y Hienz (25), han sugerido que para identificar el sexo corractamente, los estudios de cromatina preferencialmente deben hacerse sobre el endotelio y tejido conectivo de la vellosidad placentaria.

No obstante, las determinaciones de cromatina en individuos con gienitales externos dudosos, no necesariamente proporcionan una respuesta práctica. Mediante estas investigaciones de cromatina, no es posible diferenciar al pseudohermafroditismo del her. mafroditismo verdadero.

Cuando un individuo tiene cromatina negativa, genitales extarnos aparentemente ginecoides y si se puede descartar el hermafroditismo verdadero y la aplasia gonadal, debemos diagnosticar un pseudohemafroditismo masculino.

Por otra parte, cuando un niño tiene cromatina positiva, con genitales externos aparentemente androides, una vez descartado el hermafroditismo verdadero, y el S'ndromo de Klinefelter, puede hacerse el diagnóstico de pseudohermafroditismo femenino.

El diagnóstico de la hiperplasia suprarrenal congénita puede hacerse siempre y cuando que la eliminación urinaria de 17 ketosteroides esté por encima de 2 a 5 miligramos, en 24 horas, debido a que los valores normales durante el periodo neo_natal, no exceden a cifras de 0,5 miligramos por día. Si estos valores se encuentran en niveles dudosos, la demostración de pregnanetriol en la orina, puede confirmar el diagnóstico de esta entidad. Una vez hecho el diagnóstico, se le asigna al individuo el sexo femenino y se instituye una terapéutica adecuada, con cortisona. Si el clítoris se encuentra notoriamente aumentado de tamaño, su resección se hace imperiosa, antes de que la niña en cuestión complete sus dos años de edad. 
Eliminados los casos de pseudohermafroditismo femenino, debidos a hiperplasia suprarrenal congénita, nos quedan por resolver los casos de hermafroditismo verdadero, así como también los ca. sos de pseudohermafroditismo femenino, no debidos a hiperplasia suprarrenal.

Las características de los genitales externos: según Wilkins (26), parecen darnos la respuesta práctica más acertada. El ha expresado que la anatomía de los genitales externos, proporciona el mejor diagnóstico clínico y práctico para la asignación del sexo, haciendo caso omiso de tipo de las gonadas, cromatina o estructura de los genitales externos.

No obstante, mediante este sistema, se le asigna el sexo masculino a todos los casos de pseudohermafroditismo femenino, no debidos a hiperplasia suprarrenal congénita, a pesar de que estos individuos desarrollan su pubertad en sentido femenino y que por medio de un tratamiento quirúrgico apropiado, pueden ser transformados en mujeres de apariencia normal.

En los individuos con hermafroditismo verdadero y pseudohermafroditismo masculino, es esencial considerar la potencialidad de desarrollo que los genitales externos presentan durante la pubertad, ya que esta última puede hacerse en sentido androide o ginecoide.

Se ha observado que cuando los genitales externos en indi. viduos con pseudohermafroditismo masculino, tienen una apa-iencia femenina, sus teztículos son capaces de secretar estrógenos. Hay casos en que la eliminación urinaria de los 17 ketosteroides, puede llegar a cifras de 20 o más miligramos por d'a, aun así, estos individuos son susceptibles de prezentar una pubertad ginecoide.

Hay quienes aconsejan, además, que a todos los individuos con ambigüedad genital, debe serles asignado el sexo femenino. La razón para ello, se basa en que se hace más fácil y práctico transformar a dichos individuos en mujeres, por medio de una terapéutica adecuada, hormonal y quirúrgica.

Transformarlos en hombres se hace la mayoría de las veces, cosmética y funcionalmente imposible. Es más fácil crear una vagina artificial que corregir un hipospadias e improvisar una ure. tra que se aproxime al giande. Estos últimos, además, requieren generalmente la construcción quirúrgica de un escroto, el cual debe ser llenado con gonadas plásticas de acrílico.

Wilkins (22), comenta a este rezpecto "que no es aconsejable convertir a un individuo hacia el sexo masculino, con un miem- 
bro inapropiado o no bien desarrollado. Cualquier intento que se haga a este respecto condienará al individuo a una vida miserable".

Si el "sexo femenino" fuere asignado a todos los pseudohermafrodits y hermafroditas verdaderos, incluyendo al pseudoher. mafroditismo femenino debido a hiperplasia suprarrenal congénita, se asignaria correctamente el sexo en todos los pseudohermafroditas femeninos y masculinos que presentaren genitales externos de apariencia ginecoide. Por otro lado, el grupo restante de pseudohermafroditas masculinos, con genitales externos aparentemente androides, con muy pocas excepciones, no pueden ser capacitados para desempeñar sus actividades masculinas, en cuanto a la función y fertilidad se refiere.

Respecto a la asignación del sexo, en virtud de la apariencia de los genitales externos, Wilkins (26), recomienda, que una vez descartados los casos de pseudohermafroditismo femenino, debidos a hiperplasia suprarrenal congénita, el paciente debe ser sometido a cuidadoso estudio. Estos estudios comprenden exámenes ure.. troscópicos, vaginoscópicos, así como también estudios roetnográficos.

Wilkins aconseja, lo mismo que Gross y Meeker (27), que en los casos dudosos debe hacerse una laparatomía exploradora para definir la naturaleza de los genitales internos. No obstante, como hemos expresado anteriormente, no consideramos que una laparatomía se haga necesaria durante la vida pre-puberal, para confrontar un diagnóstico en las diferentes ambigüedades del sexo. Debemos anotar, que por medio de la observación de la gonada, no es posible determinar la potencialidad funcionante de la misma, así como tampoco su capacidad de desarrollar la pubertad en un sentido o en otro.

Debido a las muchas controversias que algunos de los procedimientos anteriores presentan, queremos esbozar lo que en nuestro concepto constituye un sistema práctico para la rápida asignación del sexo, en individuos con genitales externos dudosos.

Primero: cuando un individuo presenta criptorquidismo, hipos.padias, un pene adecuado y cromatina negativa, el sexo masculi.. no debe serle asignado. Antes de que $e^{1}$ individuo alcance la edad escolar, las gonadas criptorquídicas deben ser sometidas a una biopsia y si en ella no aparecen elementos ováricos el descenso de éstas debe ser intentado. Si por el contrario en dicha gonada se encuentran estructuras ováricas, o el testículo no puede ser descendido al escroto, ésta debe ser extraída. 
Segundo: Cuando un individuo con cromatina negativa, pre. senta gonadas escrotales o labio-escrotales y tiene además, un pene adecuado, debe asignársele el "sexo masculino". La corrección de la hipospadia o del seno urogenital debe ser hecha antes del comienzo de la vida escolar. Cuando el individuo en cuestión presente cromatina positiva, el sexo masculino debe asignársele también, haciéndose además la cirugía plástica imperativa.

Las gonadas deben ser sometidas a biopsia, y si algunos elementos ováricos se hallaren presentes, dichas gonadas deben extraídas.

Tercero: A las ambigüedades del sexo restantes, de acuerdo con este programa, debe serles asignado el sexo femenino. En los casos de pseudohermafroditismo femenino debidos a hiperplasia suprarrenal congénita, un tratamiento apropiado debe ser iniciado, tan pronto como el diagnóstico haya sido establecido. En estos casos, un tratamiento supresivo con cortisona, permite que los geritales se desarrollen satisfactoriamente durante la pubertad, en un sentido ginecoide.

Si el clitoris se encuentra apreciablemente aumentado de ta. maño, su extracción debe hacerse de preferencia antes de los dos años de edad.

Cuarto: una vez excluidos los casos anteriores, nos quedan por considerar los individuos con hermafroditismo verdadero, así como también los pseudohermafroditas que no hayan llenado los equisitos de los grupos precedentes.

En ellos, el tratamiento permite contemporizar un poco más, por lo tanto, los respectivos padres deben ser ampliamente preparados desde el punto de vista sicológico y moral para que estén capacitados a aceptar los diferentes tratamientos quirúrgicos u hormonales que sean del caso. Si se trata de extraer un clitoris hipertrófico, o el pene, debemos recordar que dicha extracción debe hacerse antes de los diez y ocho meses de edad, o mejor dicho, antes del establecimiento del "género". Si se hace necesario construir, ampliar, o comunicar una vagina, estos procedimientos no deben hacerse hasta el comienzo de la pubertad; para este tiempo, una laparatomía se justifica, en el caso de que se hiciere ne. cesario reafirmar el sexo asignado. Mediante dicha intervención se deben extraer los testículos, o las gonadas que presenten los dos elementos (tejido ovárico y testicular).

Sobra decir que si las gonadas son extraídas, se hace indispensable la extracción del útero. En algunas ocasiones, cuando la comunicación vaginal del útero existe o se hace posible por medio 
de una intervención, el útero debe ser conservado para que más tarde, con la terapia hormonal, se logre obtener la aparición periódica de sangre uterina.

Una vez extraídas las gonadas, las pacientes deben ser some. tidas a un tratamiento cíclico de estrógenos, para así complementar la pubertad y evitar la osteoporosis y otros trastornos en. docrinos.

La extracción de los testículos en este cuarto grupo, debe ha cerse más wecozmente, tan pronto eomn algún signo de androg?. nización se haga presente. Si, por el contrario, estos testículos no son funcionantes, su extracción puede esperar hasta el comienzo de la pubertad. En este último caso es necesaria la gonadectomía, para evitar los riesgos de malignidad, tan frecuentes sn un testículo criptorquídico.

No debe ser olvidado el aspecto religioso cuando se trata de ia extracción de las gonadas en un individuo. Para ello es aconse. jable asesorarse siempre de una autoridad eclesiástica, antes de someter a un paciente a castración o a un cambio de sexo.

Desde el punto de vista médico-legal, la castración de un individuo, por indicación médica, es un problema que aún no ha sido resuelto, y del cual pueden provenir serias complicaciones legales. Es aceptado que los padres puedan dar dicha autorización, mediante su derecho de custodia sobre menores; no obstante, esto no descarta el hecho de que un individuo sometido a tal procediiniento, pueda acusar a su médico de mala práctica cuando llegue a su mayoria de adad.

Wilkins (28), a este respecto manifiesta que "es justificable a extracción de una gonada que se opone al hábito general, o deseo sexual de su poseedor".

Hay varias opiniones respecto a la determinación del sexo le. gal, para un individuo. Armstrong (30), por ejemplo, estima que el factor determinante para la asignación del sexo legal en un individuo intersexual, depende de la estructura anatómica de sus gonadas; Lowrie (31) añade que ei individuo legalmente debe ser considerado como hombre si es poseedor de testículos. Por otro Lado, hay quienes sugieren que el sexo debe ser asignado en base de los estudios de cromatina. Los individuos a los cuales se les asigna el sexo en virtud de los estudios de cromatina, pueden ser a.creedores de serios traumatismos sicosexuales, como puede ocurrir si se le asigna el sexo legal masculino a un individuo quien con sindrome de Turner, haya sido tratado apropiadamente con s strógenos 
El sexo legal asignado mediante el certificado del nacimiento, en algunas ocasiones debe ser modificado, dabido a que pueden presentarse cambios espontáneos al sexo opuesto en individuos que prsentan diferentes problemas endocrinos, o que mediante una cuidadosa revaluación del individuo, se considere que su sexo deba ser cambiado. En uno y otro caso, estos cambios deben hacerse solamente bajo la asesoría de un psiquiatra y aun así, muchas veces se hace imposible evitar serios trastornos sicológicos como consecuencia de estoz cambios.

\section{Reasigra?ción del sexo}

Es frecuentemente necesario hacer una nueva asignación del sexo, bien sea porque el médico considere que el sexo asignado no fue el apropiado, o porque los padres no deseen el sexo asignado debido a que ias características morfológicas del individuo no con. cuerdan con su sexo. En ambos casos debemos confrontar el problema de la reasignación. Esta debe hacer e antes de los dieciocho meses de edad, ya que el género no se ha establecido aún en єsta época, facilitando la adjudicación del nuevo sexo. La reasignación debe hacerse una vez que los padres del infante hayan comprendido ampliamente ei problema y habiendo firmado de antemano el permiso para tal procedimiento. Una vez obtenido el permiso, deben hacerse los arreglos necesarios para la cirugía 0 terapia endocrina requerida. Todos los documentos deben ser transformados, y un nuevo certificado de nacimiento expedido.

\section{Reasignación del sexo después de que el "género" haya sido establecido}

Como dijimos anteriormente, el "género" se estabiece en la mayor parte de los niños, cerca de los dos años de edad. La reasignación después de esta época, puede traer serios compromisos sicológicos, por lo tanto la asistencia siquiátrica se hace indispensable.

Avanzada la niñez, el "género" es irreversible, por lo tanto, un cambio de sexo debe ser evitado.

\section{Solicitudes voluntarias de individuos para la reasignación dei sexo}

Cuando un cambio de sexo es deseado bajo estas circunstancias, es porque con seguridad ha habido un establecimiento defectuoso del "género" durante los primeros años. 
Estas solicitudes deben ser consideradas favorablemente cuanàa los genitales, funcional y quirúrgicamente, son susceptibles a ser adaptados al nuevo sexo.

Los estados sicosexuales, homosexualidad y transvestismo, en individuos morfológica y fisiológicamente normales, no son indi. cación para la reasignación del sexo.

\section{Comentario}

En este artículo hemos querido sintetizar los diferentes problemas de la asignación del sexo.

Primordialmente queremos poner en claro que el verdadero sexo de un individuo, no es necesariamente el que concuerda con sus cromosomas, gonadas, producción hormonal, morfología de los genitales externos o internos.

Hemos igualmente clasificado ocho tipos de ambigüedades del sexo, las cuales en nuestro concepto facilitarán la clasificación y sgrupación de individuos con ambigüedades genitales.

Esperamos que este escrito haya sabido despertar algún interés respecto a este complejo problema, el cual, por ser de baja incidencia, no se le ha dado la importancia que merece, cosa que puede traer a dichos indviduos graves perjuicios síquicos y morales, no sólo para ellos sino para la sociedad que los rodea, cuando por negligencia del médico y del medio, no se tratan adecuadamente.

\section{REFERENCIAS}

1. BARR, M. L., and BERTRAM, E. G.-Nature 163: 676. 1949.

2. PLUNKETT, E. R., and BARR, M. L.-Anat. Rec. 124: 348. 1956 (Abstract).

3. BRADBURY, J. T., BUNGE, R. G. and BOCCABELLA, R. A.-J. Clin. Endocrinol 16: 698. 1956.

4. PLUNKETT, E. R., and BARR, M. L.-Lancet 2: 853. 1956.

5. GRUMBACH, M. M., ENGLE, E. T., BLANC W. A. and BARR, M. L. J. Clin. Endocrinol 16: 923. 1956 (Abstract).

6. JACKSON, W. P. U., SHAPIRO, B. G., UYS, C. J. y HOFFEMBERG, R.-Lancet 2: 857. 1956.

7. WILKINS, L., GRUMBACH, M. N.. y VAN WYK, J. J.-J. Clin. Endocrinol. 14: 1270. 1954.

8. POLANI, P. E., HUNTER, W. F. y LENNOX, B.-Lancet 2: 120.1954.

9. HAMPSON, J. G., MONEY, J. y HAMPSON, J. L.-J. Clin. Endocrinol. 16: 547. 1956.

10. BARR, M. L.-Citologic Test of Chromosomal Sex, Progress in Gynecology (Meigs \& Sturgis), 1957. Grune \& Straton Page 131-140. 
11. MONEY, J.-Bull. John Hopkins Hosp. 96: 253. 1955.

12. HAMBLEN, E. C.-Am. J. of Obst \& Gyn. St. Louis Vol. 74, № 6: 1228, 1244. 1957.

13. SPEMANN.-Embryonic Development and Induction, Yale University Press, New Heaven. 1938.

14. GRUMBACH, M. M., VAN WYK, J. J. y WILKINS, L.-J. Clin. Endocrinol. 15: 1161. 1955.

15. WIESNER, B. P.-J. Obst. \& Gyn. Brit Emp. 41: 876, 1934; 42: 8. 1935.

16. JOST, A.-Arch. Anat. micr. et morphol. exper. 36: 271. 1947. New York. 1953. Academic Press Inc. Vol. 8. Page. 379.

17. JOST, A. In PINCUS, G., editor.-Recent Progress in Hormone Research, New York. 1953. Acaddemic Press Inc. Vol. 8 Page 379.

18. GILLMAN, J.-Contrib. Embryol. 32: 81. 1948.

19. HAMBLEN, E. C., CARTER, F. B., WORTHAN, J. T. and ZANARTU, J.-Am. J. Obst. \& Gyn: 61: 1. 1951.

20. WILKINS, L.- "Endocrine Disorders in Childhood and Adolescence". Second. Edition. Publish. Charles, C. Thomas. 1957. Páginas 258, 88.

21. BRETNALL, C. P.-Am. J. Obst. \& Gyn. Brit. Emp. 25: 235. 1945.

22.-JAVERT, C. T. and FINN, W. F.-Cancer 4: 60.1951.

23. HOFFMANN, F., OVERZIER, C. and UHDE, G.-Gerburth u Fraunh. 15: 1.061. 1955 (Abstract) in J. A. M. A. 160: 1.535. 1956.

24. OVERZIER, C.-Acta Endocrinol. 21: 97. 1956.

25. BOHLE, A. and HIENZ, H. A.-Klin Wchnschr. 34: 981. 1956 (Abstract) in J. A. M. A. 163: 76. 1957.

26. WILKINS, L., GRUMBACH, M. M., VAN WYK, J. J., SHEPARD, T. H. and PAPADATOS, C.-Pediatries 16: 287. 1955.

27. GROSS, R. E. and MEEKER, I. A. Jr.-Pcdiatrics 16: 303. 1955.

28. WILKINS, L.-The diagnosis and Treatment of Endocrine Disorders in Childhood and Adolescence, Springfield, III, 1950. Charles, C. Thomas, Publisher.

29. ARMSTRONG, C. M.-Proc. Roy. Med. 46: 301. 1953.

30. LOWRIE, R. G.-Gynecology, Diseases and Minor Surgery, Springfield, III, 1952. Charles, C. Thomas, Publisher.

31. HAMBLEN, E. C.-Am. J. of Obst. \& Gyn. Vol. 74, № 6, Pages 1.228, 1.244. 1957 .

32. YOUNG, H. H.-Genital Abnormalities, Hermafroditism and related Adrenal diseases, Baltimore, Md. 1937. Williams and Wilkins Co.

33. BARR, M. L.-Anat. Rec. 121: 387. 1955 (abstract).

34. HAMPSON, J. G.-Bull. Jons Hopkins Hospital. 96: 265. 1955.

35. HAMPSON, J. L., HAMPSON, J. G. and MONEY J.-Bull. Johns Hopkins Hosp. 97: 207. 1955.

36. MONEY, J., HAMPSON, J. G. and HAMPSON, J. L.-Bull. Johns Hopkins Hosp. 97: 284. 1955.

37. MONEY, J., HAMPSON, J. G. and HAMPSON, J. L.-Bull. Johns Hopkins Hosp. 98: 43. 1956.

39. HAMPSON, J. G., MONEY, J. and HAMPSON, J. L.-J. Clin. Endocrinol. 16: 547. 1956.

40. MASTERS. W. H.-In Engle I. T. and PINCUS GREGORY editors.-Hormones and the aging process, New York, 1956, Academic Press, Inc. 
41. BARR, M. L.-Lancet 1: 47. 1956.

42. KLEBS, E.-Handbuch der pathologiscchen Anatomic, Berlín, 1876. August Hirschwald.

43. JOST, A.-Arch. Anat. Micr. el Morphol. Exper. 39: 577. 1950.

44. LILLIE, F. R.-J. Exper. Zool. 23: 371. 1917.

45. PRUNTY, F. T. G., Mc SWINEY, R. R. and CLYTON, B. E.-J. Clin, Endocrinol. 13. 1.480. 1953.

46. TURNER, H. H.-Endocrinology 23: 566. 1938.

47. AMELAR, R. D.-J. Urol. 76: 174. 1956.

48. KOZOLL, D. D.-Arch. Surg. 45: 578. 1942.

49. GREENE, R., MATHEWS, D., HUGHEESDON, P. E. and HOWARD, A. Brit. J. Surg. 40: 263.

50. GREENE, R., MATHEWS, D., HUGHESDON, P. E. and HOWARD, A. Brit. J. Surg. 41: 548. 1954.

51. RAYNAUD, A. and Frilley, M.-Ann. Endocrinol. 8: 400. 1947.

52. KLINEFELTER, H. F., Jr., Reifenstein, E. C. Jr. and Albright, F. J. Clin. Endocrinol. 2: 615. 1942.

53. BUNGE, R. G. and BRADBURY, J. T.-J. Clin. Endocrinol. 16: 1.117. 19.56 .

54 NELSON, W. O.-Acta Endocrinol. 23: 227. 1956.

55. NELSON, W. O.-Personal comunication. Nov. 24. 1956.

56. PLUNKETT, E. R.-Personal comunication, Nov. 24. 1956.

57. MAKOWSKI, E. L., PREM, K. A. and KAISER, I. H.-Science 123: 542. 1956.

58. SACHS, L. SERR, D. M. and DANON, M.-Science 123: 548. 1956.

59. DEWHURST, C. J.-Lancet. 1: 471. 1956.

60. BARR, M. L. and HOBBS, G. F--tancet 1; 1.109. 1954. 